\title{
APC mutation spectrum of Norwegian familial adenomatous polyposis families: high ratio of novel mutations
}

Per Arne Andresen · Ketil Heimdal · Kristin Aaberg • Katrine Eklo • Sarah Ariansen • Alexandra Silye · Olav Fausa - Lars Aabakken ·

Stefan Aretz · Tor J. Eide · Tobias Gedde-Dahl Jr.

Published online: 30 June 2009

(C) Springer-Verlag 2009

\section{Erratum to: J Cancer Res Clin Oncol}

\section{DOI 10.1007/s00432-009-0594-4}

Unfortunately, the fourth author's name had been misspelled. The correct version is Katrine Eklo and not Kristin Eklo as published.

The online version of the original article can be found under doi:10.1007/s00432-009-0594-4.

P. A. Andresen $(\varangle) \cdot$ S. Ariansen $\cdot$ A. Silye $\cdot$ T. J. Eide Pathology Division, University Hospital of Oslo-Rikshospitalet, 0027 Oslo, Norway

e-mail: per.arne.andresen@ rikshospitalet.no

K. Heimdal

Department of Medical Genetics,

University Hospital of Oslo-Rikshospitalet, 0027 Oslo, Norway

K. Aaberg $\cdot$ K. Eklo

Department of Pathology,

University Hospital of Northern Norway, 9037 Troms $\varnothing$, Norway

O. Fausa $\cdot$ L. Aabakken

Department of Medicine,

University Hospital of Oslo-Rikshospitalet, 0027 Oslo, Norway

S. Aretz

Institute of Human Genetics,

University of Bonn, 53111 Bonn, Germany 